\title{
O DANO MORAL PREVIDENCIÁRIO E A EFETIVAÇÃO DOS DIREITOS SOCIAIS NO ESTADO EM CRISE
}

\author{
Aline de Paula Santos Vieira ${ }^{1}$ \\ Daisy Rafaela da Silva ${ }^{2}$
}

\begin{abstract}
RESUMO: A proteção à dignidade da pessoa humana, aliada aos demais princípios constitucionais norteadores do Direito Previdenciário, tem sido cada vez mais utilizada como instrumento de efetivação dos direitos sociais relativos à concessão e/ou revisão de benefícios previdenciários, os quais, diante de um estado em crise, devem ser efetivamente observados. O presente artigo traz uma reflexão acerca do instituto do Dano Moral Previdenciário, que vem se tornando evidente nas relações previdenciárias, sob o enfoque da efetivação dos direitos sociais, analisando o status constitucional conferido ao tema. Traz, também, considerações acerca das definições doutrinárias e jurisprudenciais acerca da definição do dano moral previdenciário, quanto à responsabilidade civil do Estado nesses casos, bem como quanto às hipóteses de cabimento da indenização por dano moral decorrente de vício nos processos de concessão de benefício, buscando justificativas para o referido instituto, enquanto reparador de violações às garantias fundamentais do cidadão, as quais tem sido frequentes diante da atual crise nacional.
\end{abstract}

Palavras-chave: Dano Moral. Previdência Social. Direitos Sociais. Crise.

\section{THE PREVENTIVE MORAL DAMAGE AND THE EFFECTIVENESS OF SOCIAL RIGHTS IN THE STATE IN CRISIS}

ABSTRACT: The protection of the dignity of the human person, together with the other constitutional principles guiding Social Security Law, has been increasingly used as an instrument for the implementation of social rights related to the granting and / or revision of social security benefits, which, faced with a state in crisis, must be effectively observed. This article presents a reflection about the Institute of Moral Social Security Damage, which is becoming evident in social security relations, under the focus of the effective social rights, analyzing the constitutional status conferred to the theme. It also brings into consideration the doctrinal and jurisprudential definitions regarding the definition of social security damage, the civil liability of the State in these cases, as well as the hypothesis of reparation for moral damages resulting from a vice in

\footnotetext{
${ }^{1}$ Mestranda em Direitos Sociais, Econômicos e Culturais pelo Centro Universitário Salesiano de São Paulo (UNISAL). Membro dos Grupos de Pesquisa "Minorias, discriminação e efetividade de direitos" e "Direitos Humanos" cadastrados junto ao CNPq. Professora do Curso de Pós-Graduação do Curso Êxito São José dos Campos e Curso Preparatório para concursos JV Guaratinguetá. Advogada militante nas áreas Previdenciária e Trabalhista. E-mail: alinevieira.advocacia@gmail.com.

${ }^{2}$ Doutora em Direito. Mestre em Direitos Difusos e Coletivos. Professora Titular e Pesquisadora do Programa de Mestrado em Direito do Centro Universitário Salesiano de São Paulo (UNISAL), de Lorena/ SP e nos Cursos de Graduação e Pós-Graduaçao. Professora Doutora III da EEL USP. Coordenadora do Núcleo de Estudos de Direitos Humanos do UNISAL - Lorena-SP. Líder do Grupo de Pesquisa Direitos Humanos cadastrado junto ao CNPq. E-mail: daisyrafa1 @ hotmail.com.
} 
the processes of granting benefit, seeking justifications for this institute, as a remedy for violations of the fundamental guarantees of the citizen, which have been frequent in the current national crisis.

KEY WORDS: Moral damage. Social Security. Social rights. Crisis.

\section{INTRODUÇÃO}

A maioria dos princípios informadores da Seguridade Social encontram-se na Constituição Federal, mais especificamente no artigo 194, sendo tratados pelo constituinte originário como objetivos do sistema. São eles:

\footnotetext{
I - universalidade da cobertura e do atendimento;

II - uniformidade e equivalência dos benefícios e serviços às populações urbanas e rurais;

III - seletividade e distributividade na prestação dos benefícios e serviços;

IV - irredutibilidade do valor dos benefícios;

$\mathrm{V}$ - equidade na forma de participação no custeio;

VI - diversidade da base de financiamento;

VII - caráter democrático e descentralizado da administração, mediante gestão quadripartite.
}

O sistema, como não poderia ser diferente, para alcançar a sua maior efetividade, deveria pautar-se nos princípios, nos comandos determinados por eles, a origem das normas infraconstitucionais.

Ocorre que no caminho da criação da norma até a sua efetivação prática, frequentemente os princípios se perdem, a proteção objetivada no texto constitucional toma nova forma, influenciada por interesses outros que não se relacionam com o bem estar social, e muito menos com o respeito à dignidade da pessoa humana.

Como consequência, são violados os Direitos Sociais, trazendo prejuízos de ordem material e, sobretudo, moral aos cidadãos.

$\mathrm{Na}$ seara do Direito Previdenciário as violações aos princípios constitucionais trazem consequências ainda mais sérias, vez que se tratam de direitos de caráter alimentar, destinados à sobrevivência dos segurados e seus dependentes, atingidos pelas mais diversas contingências.

Assim, na busca pela garantia dos direitos fundamentais do cidadão, a inquietude dos operadores do direito diante de tantas irregularidades trouxe o instituto do Dano Moral ao Direito Previdenciário. 


\section{A violação dos Princípios Constitucionais no Direito Previdenciário}

Os Princípios podem ser definidos como espécie de normas jurídicas com interpretação mais abstrata, geral e indeterminada que as regras, por não disciplinarem diretamente as conditas humanas, dependendo de uma intermediação valorativa do intérprete para a sua aplicação.

Segundo De Plácido e Silva (1993, p. 447):

No sentido jurídico, notadamente no plural, quer significar as normas
elementares ou os requisitos primordiais instituídos como base, como alicerce
de alguma coisa. E, assim, princípios revelam o conjunto de regras ou
preceitos, que se fixaram para servir de norma a toda espécie de ação jurídica,
traçando, assim, a conduta a ser tida em qualquer operação jurídica. (...)
Princípios jurídicos, sem dúvida, significam os pontos básicos, que servem de
ponto de partida ou de elementos vitais do próprio direito.

E Rizzatto Nunes (2002, p. 37):

Da mesma maneira que os princípios ético-jurídicos mais gerais, os princípios constitucionais são o ponto mais importante do sistema normativo. Eles são verdadeiras vigas mestras, alicerces sobre os quais se constrói o sistema jurídico. Os princípios constitucionais dão estrutura e coesão ao edifício jurídico. Assim, devem ser obedecidos, sob pena de todo o ordenamento jurídico se corromper.

Das conceituações há que se extrair, por conseguinte, que o ponto de partida do legislador deve ser pautado na interpretação teleológica dos princípios, ou seja, a observância da hierarquia das normas, passa pela fiel interpretação principiológica.

Passíveis de sofrer prejuízo de ordem moral, aqueles que são prejudicados nos processos de concessão de benefício previdenciário (segurados e dependentes), indenização esta que deve obedecer ao caráter pedagógico da punição, a fim de coibir a reiteração das práticas lesivas, tendo em vista o caráter alimentar do benefício previdenciário, elevado a status constitucional, por se tratar, primacialmente de Direito Social.

Os sujeitos da relação previdenciária, passíveis de sofrer dano moral, são os segurados, seus dependentes e sucessores:

O sujeito ativo é aquele que poderá ajuizar a ação como vítima do dano causado. Assim, poderá figurar como sujeito ativo no polo da relação processual o segurado, o dependente, o contribuinte e seus sucessores. Conveniente advertir que a reparação só pode ser proposta por pessoa titular 
do direito ofendido, pois se trata de direito personalíssimo. (CAMPOS. 2013, p. 124)

Como vítima, aquele que for lesado na sua honra, é legitimado a buscar a devida reparação, por se tratar de relação personalíssima:

(...) somente o titular da pretensão iniciará o procedimentos administrativo ou judicial. Sendo intransferível a moralidade conspurcada, a relação jurídica é nitidamente intuitu personae. (MARTINEZ. 2009, p. 60)

Situação frequente quando se trata de demanda judicial para concessão de benefícios previdenciários, de forma revoltante, é a morte do segurado antes mesmo do reconhecimento do direito pleiteado, o que leva à habilitação de seus sucessores no processo. Sobre o contexto, os Tribunais já tem se manifestado:

(...) a jurisprudência vem admitindo que os sucessores do ofendido por dano moral proponham ou o sucedam na ação judicial de reparação. Uma vez proposta a ação e, considerando a notória demora na conclusão definitiva dos processos judiciais, é bem possível que o segurado ou dependente, por vezes já idoso ou em estado terminal de vida, não exista mais ao final do feito, o que obriga a possibilidade de que seus sucessores sejam habilitados em seu lugar, no caso de falecimento do autor da ação. (CAMPOS. 2013, p. 125)

Perfeitamente crível que o abalo moral sofrido pelo segurado quando da concessão tardia de um benefício, ou quando da negativa injustificada pela Autarquia, traz consequências também aos seus dependentes e sucessores, posto que impedidos de obter o devido amparo do seu provedor.

(...) fácil aceitar que pais, esposas, filhos e irmãos do ofendido direto tenham titularidade para pleitear indenização por dano moral indireto e reflexo. (THEODORO JÚNIOR. 2001, p. 09)

Aqui, jamais se poderá violar a dignidade da pessoa humana sob a falácia da banalização do dano moral, e sim reconhecer o desrespeito ao ser humano hipossuficiente diante das regras firmadas pelo Estado, quando o assunto é prestação alimentícia, direito social fundamental.

Ingo Wolgang Sarlet (2015. p. 60), conceitua dignidade da pessoa humana como:

(...) qualidade intrínseca e distintiva de cada ser humano que o faz merecedor do mesmo respeito e consideração por parte do Estado e da comunidade, implicando, neste sentido, um complexo de direitos e deveres fundamentais que assegurem a pessoa tanto contra todo e qualquer ato de cunho degradante 
e desumano, como venham a lhe garantir as condições existentes mínimas para uma vida saudável, além de propiciar e promover sua participação ativa e co-responsável nos destinos da própria existência e da vida em comunhão com os demais seres humanos.

É notório que o Direito Previdenciário vem galgando posição de destaque dentre os ramos do Direito, deixando a sociedade de pensar na proteção do Judiciário somente com relação a questões de Direito Civil ou Direito Penal. Assim:

\begin{abstract}
O debate sobre a previdência social tem encontrado cada vez mais abertura no meio acadêmico. Antes restrito a tecnocratas, esse sistema de proteção social finalmente tem guarida na seara jurídica, decorrência natural de sua expressa previsão como direito social no art. $6^{\circ}$ da Constituição de 1988 , aliada ao reconhecimento de sua jusfundamentalidade. Tal avanço é perceptível pelo aumento da produção jurídica sobre a matéria nos últimos anos, pois o estudo do direito previdenciário era algo limitado a poucos especialistas e de escasso desenvolvimento. Um evidente reflexo desse passado inglório é o fato de essa disciplina, até os dias de hoje, ainda não se encontrar entre as matérias obrigatórias na maioria das faculdades de direito. (IBRAHIM. 2014, p. 22)
\end{abstract}

Neste contexto, a garantia dos direitos da pessoa humana enquanto segurado da Previdência é assunto recorrente e que tem frequência nas pautas dos Tribunais Superiores, dos quais é exigido pela sociedade posicionamento consolidado acerca de diversos temas de Direito Previdenciário.

Entretanto, com a citada evolução, o Direito Previdenciário praticado na atualidade distanciou-se daquele almejado no Texto Constitucional de 1988 e defendido nas obras doutrinárias da lavra de Martinez, de Agostinho e Salvador, de Balera, por exemplo, dissociando-se, na prática, de todo o legado constitucional.

O cenário atual é impactante, repleto de vícios constitucional e administrativamente inadmissíveis que ferem os direitos do cidadão, violando a dignidade da pessoa humana, também prevista na Constituição, culminando em extremo desrespeito aos Direitos Sociais garantidos como cláusulas pétreas.

Há na doutrina distinção entre Direitos Fundamentais e Direitos Humanos, considerando aqueles os direitos mínimos reconhecidos por um determinado ordenamento jurídico e estes os direitos supranacionais, vistos sob o prisma da ordem internacional:

Os Direitos Previdenciários qualificam-se como direitos sociais, que, por sua vez, são classificados como direitos fundamentais dos seres humanos. (FOLMAN. 2008, p. 285 e 289) 
De natureza alimentar, os direitos previdenciários, na condição de direitos fundamentais, exigem efetiva aplicação, observando os princípios constitucionais que os regem, sobretudo o da universalidade da cobertura, devendo atender a todos que forem atingidos pelas mais diversas contingências atendidas pela Previdência.

\begin{abstract}
A fundamentalidade dos direitos previdenciários é inequívoca, porquanto se tratam de direitos básicos para a sobrevivência das pessoas. Os benefícios previdenciários são direitos subjetivos do segurado e seus dependentes no momento em que ocorrer o fato gerador, sendo seus proveitos de natureza alimentar. Na condição de fundamentais, os direitos previdenciários exigem a aplicabilidade imediata e principalmente efetivação, de modo a torná-los concretos a fim de dignificar a pessoa humana. (CAMPOS. 2013, p. 91)
\end{abstract}

Deparamo-nos com diversas situações irregulares como a demora na prestação administrativa que pode levar a óbitos nas filas de espera por um benefício, suspensão indevida de pagamentos ou benefícios, descontos indevidos sem justificativas, extravio de documentos do processo e até mesmo do processo inteiro, presunção de fraude na concessão do benefício sem o devido processo legal, e não raro o atendimento precário e desatencioso que expõe os segurados e seus dependentes ou representantes a situações vexatórias, de maus tratos, e tantos outros casos.

Indubitavelmente as referidas situações ocasionam prejuízos de ordem moral e material aos segurados, vítimas de um sistema cercado de vícios, os quais merecem reparação, observados o caráter alimentar e urgente das pendências previdenciárias.

\title{
2. Dano Moral Previdenciário e o Bem Estar Social
}

Da necessidade de se socorrer da Previdência na busca o direito à concessão, revisão ou restabelecimento de benefício, a pessoa humana, que deveria estar amparada pelos ditames dos princípios que regem os direitos, se depara com os obstáculos impostos pela legislação infraconstitucional que regulamenta os requisitos para que se alcance o bem estar social e a efetivação da cidadania por este meio.

Dos obstáculos surgem os prejuízos de ordem material, bem como, e da mais grave consequência, os de ordem moral, ensejando, portanto, o direito à indenização.

Urge resgatar, nesta seara, a vontade primária do constituinte originário. Nas palavras de Frederico Amado: 
Com o advento do constitucionalismo pós-positivista, os princípios passaram à categoria de normas jurídicas ao lado das regras, não tendo mais apenas a função de integrar o sistema quando ausentes as regras regulatórias, sendo agora dotados de coercibilidade e servindo de alicerce para o ordenamento jurídico, pois axiologicamente inspiram a elaboração das normas-regras. (2015, p. 29)

Com status constitucional, o dano moral tem previsão no art. $5^{\circ}, \mathrm{V}$ e $\mathrm{X}$, do Diploma Maior:

V - é assegurado o direito de resposta, proporcional ao agravo, além da indenização por dano material, moral ou à imagem;

(...)

$\mathrm{X}$ - são invioláveis a intimidade, a vida privada, a honra e a imagem das pessoas, assegurado o direito a indenização pelo dano material ou moral decorrente de sua violação.” (VADE MECUM, 2015, p. 06)

Pode-se conceituar, o dano moral, como prejuízo, estrago aos bons costumes, à honestidade de outrem, temos que é reparável todo e qualquer dano na esfera civil, tenha atingido o patrimônio ou a personalidade. Porém, é imperiosa a análise de cada caso concreto, procedendo-se à correta apreciação do ocorrido para verificar se realmente se trata de dano moral, passível de reparação ou, tratam-se de meros transtornos, dissabores, que acontecem no cotidiano do ser humano:

Dano moral é o prejuízo jurídico ilicitamente causado aos atributos da personalidade do ser humano e da pessoa jurídica. (MARTINEZ. 2009, p. 29)

Dano moral nada mais é do que a ofensa à dignidade da pessoa humana, posto que esta é a base dos valores morais que compõem a sociedade.

O abalo moral é aquele que atinge a órbita interna da pessoa, gerando um sentimento de derrota e pesar que lhe impõe uma alteração de comportamento ou psíquica, causando prejuízo à sua parte social ou afetiva. (CAMPOS. 2013 p. 92)

A responsabilidade civil do Estado surge de atos comissivos ou omissivos de seus agentes que ocasionem lesão aos direitos de outrem, seja por culpa ou dolo, sendo, portanto, objetiva. 
Celso Antônio Bandeira de Melo trata da violação ao princípio da Dignidade da Pessoa Humana da seguinte forma:

Violar um princípio é muito mais grave que transgredir uma norma qualquer. A desatenção ao princípio implica ofensa não apenas a um específico mandamento obrigatório, mas a todo sistema de comandos. É a mais grave forma de ilegalidade ou inconstitucionalidade, conforme o escalão do princípio atingido, porque representa insurgência contra todo o sistema, subversão de seus valores fundamentais, contumélia irremissível a seu arcabouço lógico e corrosão de sua estrutura mestra. Isto porque, com ofendê-lo, abatem-se as vigas que o sustêm e alui-se toda a estrutura nelas esforçadas. (Apud AGOSTINHO; SALVADOR. 2015. p.51)

Maria Sylvia Zanella Di Pietro, explicita:

O serviço público não funcionou (omissão), funcionou atrasado ou funcionou mal. Em qualquer dessas três hipóteses, ocorre a culpa (faute) do serviço público ou acidente administrativo, incidindo a responsabilidade do Estado independentemente de qualquer apreciação da culpa do funcionário. Quando uma pessoa sofre um ônus maior do que o suportado pelas demais, rompe-se o equilíbrio que necessariamente deve haver entre os encargos sociais; para restabelecer esse equilíbrio, o Estado deve indenizar o prejudicado, utilizando recursos do erário público. (Apud CAMPOS. 2013. p. 99)

Ao responsabilizar o Estado pelos danos causados a outrem, deve-se buscar atingir a finalidade precípua dessa condenação, qual seja, o restabelecimento do equilíbrio violado pelo dano.

Assim, tem-se que a responsabilidade do Estado é objetiva, pois é dele a incumbência de fornecer as mínimas condições para que sejam efetivos os seus serviços aos cidadãos, que os mesmos sejam prestados conforme prevê o art. $37, \S 6^{\circ}$ da Constituição Federal.

(...) o Estado responde objetivamente perante um terceiro objetivamente, bastando a vítima provar o fato ou o ato lesivo, o dano e nexo causal, prescindindo da prova da culpa ou do dolo. O servidor ou o agente público responde perante o Estado subjetivamente de acordo com a sua culpa ou dolo, em ação judicial regressiva. (CAMPOS. 2013, p. 99)

No Direito Previdenciário, atualmente, é cada vez mais recorrente que não se admita considerar práticas ilícitas como meros acontecimentos do cotidiano, tendo em vista o caráter alimentar de um benefício previdenciário, não importando a sua origem. 
Tudo isso porque os Direitos Previdenciários são fundamentais, são direitos básicos à mínima sobrevivência dos segurados e seus dependentes, visando garantir a dignidade da pessoa humana, a efetivação dos direitos sociais, com aplicabilidade e efetivação imediatas.

Wladimir Novaes Martinez (2009, p. 130/183) trata das várias hipóteses que ensejam a indenização por danos morais no Direito Previdenciário, as quais merecem destaque, como a concessão tardia do benefício, descumprimento de decisão, recusa de protocolo, procrastinação da devolução de valores a restituir e compensar, perícia equivocada, erro médico, presunção de fraude, suspensão e cancelamento de benefício. ${ }^{3}$

Dentre as hipóteses acima mencionadas, importante destacar as hipóteses de grave prejuízo moral, como erro médico, lentidão na revisão, perícia equivocada, lentidão na revisão, suspensão e cancelamento de benefícios, maus tratos ao idoso, que agridem demasiadamente o foro íntimo da pessoa humana, trazendo graves consequências, que, na maioria dos casos só agravam o infortúnio que o tenha levado a buscar amparo previdenciário.

Sendo assim, como Direito Social, o Direito Previdenciário, objetiva, principalmente, a busca do bem estar e da justiça, o que, aliado com a obrigação do Estado de cumprir suas obrigações prestacionais efetivamente à população, é que se verifica o dever de indenizar aqueles lesados pela má prestação dos serviços públicos na concessão dos benefícios previdenciários.

A Constituição Federal de 1988, em seu artigo $6^{\circ}$, traz os Direitos Sociais que são: educação, saúde, trabalho, transporte, moradia, lazer, segurança, previdência social, proteção à maternidade e à infância e assistência aos desamparados.

Neste contexto, a Previdência, em conjunto com a assistência e a saúde, constituindo a Seguridade Social, está inserida dentro da chamada segunda dimensão dos direitos constitucionais, buscando cobrir as contingências por que está sujeito o ser humano, sendo, portanto, bem relevante à vida humana, de caráter alimentar, elevado à

\footnotetext{
${ }^{3} \mathrm{O}$ Autor faz referência a diversas outras situações que geram o dever de indenizar: falta da devida orientação, atendimento desatencioso, extravio de processo, retenção de documentos, cerceamento de defesa, inobservância de súmulas, má exegese das leis, demora no encaminhamento de papéis pelo Brasil, em caso de acordos internacionais, lentidão na revisão, engano no cálculo, presunção de fraude, indeferimento de CND, crimes previdenciários, greve pública, crimes previdenciários, entidades beneficentes, inclusão no CADIN, excesso de exação, maus tratos ao idoso, anotações na CTPS, mora no seguro-desemprego e inércia do Poder Judiciário.
} 
condição de direito fundamental do homem, há de se informar pelo princípio de que o direito igual à vida de todos os seres significa também que, nos casos de doença, velhice, maternidade e etc., cada um tem o direito a um benefício condigno, independente de sua situação econômica, sob pena de não ter muito valor sua consignação em normas constitucionais.

De acordo com Ingo Sarlet:

“[...] a teoria dimensional dos direitos fundamentais não aponta, tão-somente, para o caráter cumulativo do processo evolutivo e para a natureza complementar de todos os direitos fundamentais, mas afirma, para, além disso, sua unidade e indivisibilidade no contexto do direito constitucional interno [...] Em que pese o dissídio na esfera terminológica, verifica-se crescente convergência de opiniões no que concerne à idéia que norteia a concepção das três (ou quatro, se assim preferirmos) dimensões dos direitos fundamentais, no sentido de que estes, tendo tido sua trajetória existencial inaugurada com o reconhecimento formal nas primeiras Constituições escritas dos clássicos direitos de matriz liberal-burguesa, se encontram em constante processo de transformação, culminando com a recepção, nos catálogos constitucionais e na seara do Direito Internacional, de múltiplas e diferenciadas posições jurídicas, cujo conteúdo é tão variável quanto as transformações ocorridas na realidade social, política, cultural e econômica ao longo dos tempos. Assim sendo, a teoria dimensional dos direitos fundamentais não aponta, tão-somente, para o caráter cumulativo do processo evolutivo e para a natureza complementar de todos os direitos fundamentais, mas afirma, para além disso, sua unidade e indivisibilidade no contexto do direito constitucional interno e, de modo especial, na esfera do moderno 'Direito Internacional dos Direitos Humanos.” (SARLET. 2007, p. 55).

Sob a égide dos Direitos Sociais, na contramão do princípio da contrapartida ${ }^{4}$, está o Benefício Assistencial de Prestação Continuada, comumente chamado LOAS, vez que destinado ao idoso ou à pessoa com deficiência que não tenha vertido contribuições à Previdência e não tenha meios de suprir sua subsistência por meios próprios ou por sua família, configura, também, instrumento primordial para o gozo pleno da cidadania.

A necessidade premente aos direitos providos pela Seguridade Social, passam a ser um verdadeiro direito fundamental da pessoa humana, que tem por finalidade básica o respeito a sua dignidade, por meio de ações do Estado e da sociedade para propiciar

\footnotetext{
${ }^{4}$ Princípio específico de custeio da Previdência Social, previsto no $\$ 5^{\circ}$ do art. 195 da CF, segundo o qual não poderá ser criando, majorado ou estendido a categoria de segurados nenhum benefício ou serviço, sem que haja a correspondente fonte de custeio total.
} 
condições mínimas de vida e de desenvolvimento da personalidade humana, o Estado passa a ter o dever de prestar ações nas áreas por elas englobadas, sendo que as pessoas passam a poder exigir o efetivo cumprimento delas.

Neste sentido, afirma Wagner Balera:

\begin{abstract}
Arrumadas em sistema, as três partes que compões o arcabouço - saúde, previdência social e assistência social - devem proporcionar, a todos, seguridade social. A integração das áreas que, dentro e fora do aparelho governamental, recebem a incumbência de satisfazer certos direitos sociais implica na racionalização da atividade administrativa, permitindo, destarte, melhor aproveitamento das particulares formas de proteção pelos usuários." (2009. p.11)
\end{abstract}

Mesmo em se tratando de lesão a Direitos Fundamentais Sociais, há que se evitar a banalização da indenização por danos morais, ponderando as situações concretas, pois aquele segurado que está à espera de um benefício, mas continua trabalhando, portanto, tendo outra fonte de subsistência encontra-se em situação diversa daquele que aguarda a concessão do benefício sem outra renda, não possuindo recursos para se alimentar ou custear sua medicação, recorrendo a outras formas de sobrevivências e muitas delas contra a sua vontade, por exemplo.

Os Tribunais tem recepcionado a discussão, como se observa na decisão do TRF 5, a ementa do acórdão que segue:

\begin{abstract}
ADMINISTRATIVO. PREVIDENCIÁRIO. SUSPENSÃO INDEVIDA DE BENEFÍCIOS. INDENIZAÇÃO POR DANOS MORAIS. CABIMENTO. 1. Caso em que a autora pleiteia indenização por danos morais em face da suspensão temporária de seus benefícios (aposentadoria rural por idade e pensão por morte) na via administrativa; 2. São gravíssimos os constrangimentos de aposentado, em idade provecta, que amarga a frustração de saber, por funcionário da instituição bancária, que seus proventos foram suspensos, sem qualquer prévia comunicação, mormente quando demonstrado inúmeros problemas decorrentes de tal supressão (inadimplência); 3. Reconhecido pelo próprio INSS que o ato de suspensão dos benefícios (que perdurara por 43 dias) decorrera de erro administrativo, ante a existência de homônimo, é devida a indenização por danos morais, ainda que já procedida a reativação daqueles, mantendose a condenação em R \$2.000,00 (dois mil reais); 4. Apelação improvida. (TRF5 AC 24557820134059999, Segunda Turma. Des. Federal Paulo Roberto de Oliveira Lima, Publ. 05/09/2013)
\end{abstract}

São graves e extremamente perigosos os prejuízos causados ao segurado, seja pela suspensão indevida de benefício, seja pela concessão tardia do mesmo, pelo fato de que os reflexos são de ordem financeira, de saúde e de abalo moral, aos familiares e seus dependentes, como uma avalanche que envolve a todos. Abaixo, ementa de acórdão do TRF 2: 
PREVIDENCIÁRIO - REMESSA NECESSÁRIA E APELAÇÃO CÍVEL APOSENTADORIA POR TEMPO DE CONTRIBUIÇÃO - TEMPO NECESSÁRIO COMPROVADO NOS AUTOS - INDENIZAÇÃO POR DANOS MORAIS - CABIMENTO - REMESSA E RECURSO DESPROVIDOS. I - A documentação presente nos autos comprova que à época do primeiro requerimento administrativo efetuado, o autor já apresentava tempo suficiente à sua aposentação. II - O autor faz jus ao recebimento de indenização por danos morais em razão do longo período transcorrido entre o seu primeiro requerimento administrativo e a concessão do benefício. III - Remessa necessária e apelação desprovidas. (TRF2 AC 201051018065342, 1 ${ }^{a}$ Turma Especializada. Des. Federal Antonio Ivan Athié, Publc. 17/07/2013)

O dano moral se torna ainda mais evidente nos casos em que, pela via judicial se reconhece o direito ao benefício desde a data da negativa da Autarquia, ou seja, restando incontroverso que o direito do segurado é devido desde então, comprovando equivocada a decisão administrativa.

ADMINISTRATIVO. REEXAME NECESSÁRIO. RESPONSABILIDADE CIVIL. DESCONTO INDEVIDO. BENEFÍCIO PREVIDENCIÁRIO. RESTITUIÇÃO EM DOBRO. NÃO CABIMENTO. INDENIZAÇÃO POR DANOS MORAIS. QUANTUM FIXADO. VALOR PROPORCIONAL. PRECEDENTES. HONORÁRIOS ADVOCATÍCIOS.

1. Cabível a restituição de valores descontados em duplicidade do benefício de aposentadoria, relativamente a pensão alimentícia paga erroneamente pela autarquia previdenciária. Diante da ausência de relação de consumo, não se aplica a repetição em dobro prevista pelo art. 42, parágrafo único, do CDC. 2. A Constituição Federal de 1988 acolheu a teoria da responsabilidade objetiva do Estado, no artigo 37, § $6^{\circ}$, da Constituição Federal, segundo o qual, as pessoas jurídicas de direito público e as de direito privado prestadoras de serviços públicos responderão pelos danos que seus agentes, nessa qualidade, causarem a terceiros, assegurando o direito de regresso contra o responsável nos casos de dolo ou culpa. Dessa forma, para se aferir o dever de indenizar, não é necessário perquirir sobre culpa, bastando verificar a existência de fato, dano e nexo de causalidade. 3. Configurada a prática do ato ilícito pelo INSS, que reconheceu serem indevidos os descontos, bem como o dano sofrido pelo segurado em razão da redução de seus proventos de aposentadoria. Cabível a condenação ao pagamento de indenização por danos morais. 4. A reparação civil do dano moral, diversamente do que se verifica em relação ao dano patrimonial, não visa à recomposição da situação patrimonial do lesado, mas sim reparar os danos em razão de ofensa à sua dignidade, tais como a liberdade, a integridade físico-psíquica, a solidariedade, a isonomia e o crédito. A indenização deve ser proporcional e não resultar em enriquecimento sem causa da vítima. 5 . Embora não haja critérios objetivos para a fixação dos valores, é possível estipular certos parâmetros, tomando por base situações equânimes submetidas a julgamento. O valor de $\mathrm{R} \$ 2.000,00$ arbitrado a título de indenização por danos morais encontra-se dentro dos critérios de 
proporcionalidade, capaz de cumprir a função pedagógica da reparação, não sendo excessivo ou irrisório. Precedente: TRF2, 5 ${ }^{\mathrm{a}}$ Turma Especializada, AC 200551010232330, Rel. Des. Fed. GUILHERME DIEFENTHAELER, E-DJF2R 29.10.2013. 6. Mantidos os honorários advocatícios arbitrados em valor fixo. 7. Remessa Necessária não provida. (TRF2 REO 200751080008682/RJ. 5 ${ }^{a}$ Turma Especializada. Des. Federal Ricardo Perlingeiro. Publ. 03/10/2014)

É evidente a lesão à dignidade da pessoa humana, pois, tendo em vista o caráter alimentar do benefício previdenciário, bem como o sistema da contraprestação que norteia a previdência, é inadmissível tais hipóteses sejam tratadas como situações que se encaixem nos acontecimentos do cotidiano.

Cabe, portanto, aos operadores do Direito demonstrar e divulgar a suma importância das lides previdenciárias, inclusive as administrativas, onde mais ocorrem as hipóteses que ensejam a indenização por dano moral, a fim de coibir as práticas que afrontam profundamente a dignidade da pessoa humana do segurado e dos seus dependentes.

\section{A supressão dos Direitos Sociais nas Relações Previdenciárias diante da crise}

Diante da essencialidade, fundamentalidade e da função social apresentada pelos direitos previdenciários, espera-se, através destes, a proteção da pessoa humana atingida por contingências que obstaculizam a sua sobrevivência e de seus dependentes.

Sobre a função protetora da Previdência Social:

Ademais, cumpre observar a previdência social desempenha sua função
protetora em superioridade diante dos demais mecanismos protetivos, pois a
cotização forçada aqui tem sistemática própria e estritamente vinculada ao
equilíbrio financeiro e atuarial, atendendo ao desiderato da vida digna em
respeito às limitações econômicas inerentes ao Estado Pós-Social. Admitir a
previdência social como direito fundamental é uma necessidade. Muitos
criticam o enquadramento, mas poucos conseguiriam viver em uma
sociedade sem essa. O seguro social é meio necessário e eficaz de garantia da
vida digna, firmando sua posição em todas as sociedades desenvolvidas. Indo
além, pode-se dizer que a previdência social, na sua dimensão objetiva, seria
uma garantia institucional, pois supera a solidão individualista da concepção
clássica dos direitos fundamentais, nas palavras de Paulo Bonavides, já que
as diretrizes do aparelho previdenciário e sua própria existência são também
resguardadas de alterações pelo Legislador Ordinário, em uma realidade mais
abrangente e eficaz na valoração da pessoa humana. Assim, não seria correto
divisar a existência de um direito fundamental à aposentadoria por invalidez, 
ou um direito fundamental ao salário-maternidade. A jusfundamentalidade é da previdência social como garantia institucional. Isso é de extrema importância, pois a alteração do rol de prestações é possível, com redução ou mesmo exclusão de algumas, desde que o conjunto ainda atenda às necessidades sociais existentes, capaz de assegurar a vida digna. Somente com tais garantias é que a sociedade brasileira poderá estabelecer uma ativa isonomia e a liberdade real, na qual as pessoas possam, efetivamente, implementar seus projetos de vida. (IBRAHIM. 2014, p. 32)

Estabelecido um Estado de Crise, com acentuada a escassez de recursos, e com isso, acentuada, por via de consequência, a necessidade de amparo aos hipossuficientes, em decorrência do desemprego e exclusão social, por exemplo.

No que se refere a Crise, Celestino e Silva enfatizam:

A crise é uma palavra hodiernamente trazida na mídia, nas discussões filosóficas, sociais, e no dia a dia do cidadão do mundo, que nos remota a dificuldade financeira, a falta de liquidez, e, na atualidade comumente utilizada pelo Estado para justificar a eliminação dos direitos fundamentais sociais, sob o argumento falacioso de que todos devem sacrificar direitos em virtude da malograda crise. (p. 10, 2016)

Sobre a escassez e suas consequências:

A escassez forma uma linha em comum que atravessa muitos problemas da sociedade. Eles ocorrem em diferentes culturas, condições econômicas e sistemas políticos, mas todos tem como característica a mesma escassez. Poderia haver uma lógica comum à escassez, uma lógica que opera nesses cenários diversos? A escassez captura a mente. (...) quando experimentamos qualquer tipo de escassez, somos absorvidos por ela. A mente se direciona automática e fortemente para as necessidades não supridas. Para o faminto, essa necessidade é a comida. Para as pessoas ocupadas, pode ser um projeto a ser concluído. Para quem está sem dinheiro, pode ser o pagamento do aluguel daquele mês; para o solitário, a falta de companhia. (MULLAINATHAN E SHAFIR. 2016, p. 14 e 18)

Mente capturada, os responsáveis por amenizar os efeitos da crise, ao tomar medidas de ajustes, acabam por suprimir certos direitos daqueles que se encontram em posição de hipossuficiência, não encontrando o amparo necessário do Estado. Neste sentido, Daisy Rafaela da Silva e Margareth Anne Leister afirmam:

Para a redução da desigualdade e pobreza, há mecanismos para que se possa se assegurar o mínimo existencial. Em tempos de crise, a escassez aumenta a perda de renda e recursos aumenta, aumentando, agrava-se mais a desigualdade(...) Assim, os Direitos Sociais não podem ser objeto de supressão ou flexibilização em virtude de serem fundamentais à pessoa humana, so o pilar da proibição ao retrocesso. (2017, p. 156 e p. 169)

No atual estado de crise, as medidas de combate aos seus efeitos, tem atingido negativamente os Direitos Sociais, inclusive os previdenciários, seja quando editadas medidas provisórias alterando a forma de concessão dos benefícios, como no caso da 
pensão por morte, do auxílio doença, seja por decisões dos Tribunais Superiores, como no caso da desaposentação e da aposentadoria do professor.

Mas é preciso enfatizar que,

O Estado quando pensado tinha por objetivo o de assegurar a proteção do indivíduo, o direito do Estado social fora sonhado e ordenado por tarefas de transformação social, de forma a promover a justiça, a democracia e a dignidade humana, realizando na pessoa, o objetivo central da sociedade e do Estado, o alfa e o ômega, garantido a esse mesmo indivíduo a proibição do retrocesso social, ou, no dizer de Canotilho, a contra evolução social, ou, a evolução reacionária. (CELESTINO; SILVA, 2016, p.02)

Nesta seara, o indeferimento de pedidos de benefícios, a demora na sua concessão entre as hipóteses já citadas, agravam sobremaneira as consequências de uma situação que, muita das vezes, já fugiu do controle do próprio segurado, quando somente lhe resta se socorrer do Estado.

Em momentos dessa natureza já está o segurado ou seu dependente, abalado não só materialmente como moralmente, vez que sua fonte de sobrevivência é nula, acarretando graves consequências, as quais são consideradas de irreparáveis ou de difícil reparação.

Por conseguinte merece o segurado ou seu dependente, a justa reparação.

Não se pode justificar a negativa previdenciária, ou até mesmo a mudança das regras de concessão dos benefícios, inclusive, a pretendida reforma previdenciária no estado de crise, os direitos sociais fundamentais deveriam ser intocáveis, tratados como prioridade.

\section{Conclusão}

Diante da importância das relações previdenciárias, os direitos sociais fundamentais ali tutelados, pela sua importância deveriam significar segurança àquelas que necessitam de cobertura por alguma contingência, haja vista funcionar o sistema através da contrapartida.

Infelizmente, não é assim que tem acontecido na prática, segurados e dependentes tem se encontrado desamparados, quando era o Estado, através do INSS, quem devia lhes dar apoio, seja pela idade avançada, por doença, por invalidez e outras diversas situações. Daí surge o dano moral, que deve ser reparado insistindo-se no caráter pedagógico da punição, para inibir a reiteração das práticas arbitrárias, 
desatenciosas dos que representam a autarquia previdenciária, vez que os direitos tutelados no âmbito do Direito Previdenciário são fundamentais, com status constitucional. Justamente por isso é que os operadores do Direito devem buscar incansavelmente a reparação por danos morais previdenciários, para que se possa garantir a preservação da dignidade da pessoa humana nestas relações, onde o segurado é o lado mais fraco, que precisa ser amparado.

É preciso que se faça valer todos os princípios que regem o Direito Previdenciário, vez que é obrigação do Estado prestar seus serviços com legalidade, impessoalidade, moralidade, publicidade e eficiência, conforme o preceituado no art. 37 da Constituição Federal de 1988, incluindo neste aspecto, o zelo pela direito que o cidadão tem de buscar a cobertura previdenciária.

\section{Referências}

AGOSTINHO, Theodoro Vicente e SALVADOR, Sérgio Henrique. Dano Moral Previdenciário. LTr, São Paulo. 2015;

AMADO, Frederico. Curso de Direito e Processo Previdenciário. Juspodivm, $7^{\text {a }}$ Edição. Bahia. 2015;

ATKINSON, Anthony B. Desigualdade: o que pode ser feito? Tradução de Elisa Câmara. Editora LeYa, 2015;

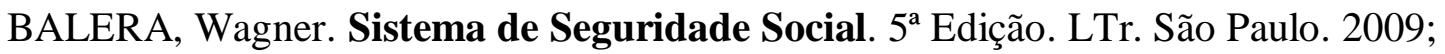

CAMPOS, Wânia Alice Ferreira Lima. Dano Moral no Direito Previdenciário. Juruá,

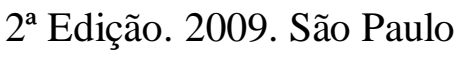

CELESTINO, Karla Alexsandra Falcão; SILVA, Daisy Rafaela. O risco à Democracia ante a mitigação de Direitos Fundamentais Sociais com a lei 13.135/2015: a perspectiva do "Estado em Crise" e aparente violação ao Princípio da Vedação ao Retrocesso. In Revista Teorias do Direito e Realismo Jurídico. N. 2, Volume 2.Curitiba: CONPEDI, 2016. Jul. dez. 2016. p.01-23.

CORREIA, José Gladston Viana. Sociologia dos Direitos Sociais: escassez, justiça e legitimidade. Saraiva. 2014. São Paulo;

FARINELI, Alexandro Menezes e MASCHIETTO, Fabia. Dano Moral

Previdenciário. Mundo Jurídico, $2^{a}$ Edição. 2013. São Paulo; 
FOLMAN, Melissa; FERRARO, Suzani Andrade. Previdência nos 60 anos da declaração de direitos humanos e nos 20 da Constituição Brasileira: homenagem ao Dr. Celso Barroso Leite. Curitiba. Juruá, 2008;

GAGLIANO, Pablo Stolze e PAMPLONA FILHO, RODOLFO. Novo Curso de Direito Civil, Volume III. Saraiva, São Paulo. 2011;

IBRAHIM, Fábio Zambitte. Curso de direito previdenciário. 10. ed. Niterói, RJ: Impetus, 2014;

LADENTHIN, Adriane Bramante de C.. Dano Moral e Direito Previdenciário, Juris Plenum Previdenciária, Ano I, Número 02 Maio 2013. p. 11-19;

MARTINEZ, Wladimir Novaes. Dano Moral no Direito Previdenciário. LTr, $2^{\mathrm{a}}$ Edição. 2009.São Paulo;

MULLAINATHAM, Sendhil e SHAFIR, Eldar. Escassez: uma nova forma de pensar a falta de recursos na vida das pessoas e nas organizações. Tradução de Bruno Casotti. Best Business. $1^{\text {a }}$ Edição, Rio de Janeiro. 2016;

NUNES, Luiz Antônio Rizzatto, $O$ princípio constitucional da dignidade da pessoa humana: doutrina e jurisprudência. São Paulo. Saraiva, 2002;

PIMENTA, Alex de Araújo. O Bem Comum na Perspectiva Previdenciária. Editora Appris. Curitiba. 2016;

SALVADOR, Sérgio Henrique. Dano Moral Previdenciário: um instituto necessário. Juris Plenum Previdenciária, Ano I, Número 02 Maio 2013. P. 21/25.

SARLET, Ingo Wolfgang. A Eficácia dos Direitos Fundamentais. Livraria do

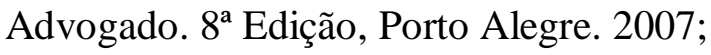

Dignidade (da Pessoa) Humana e Direitos Fundamentais na

Constituição Federal de 1988. Livraria do Advogado. 10 edição, Porto Alegre. 2015;

SILVA, De Plácido e. Vocabulário Jurídico. 12. ed. Rio de Janeiro. Forense, 1993;

SILVA, Daisy Rafaela; LEISTER, Margareth Anne. Direitos Sociais Fundamentais: da integralidade às supressões e flexibilizações no Brasil em Crise. In STRAPAZZON, Carlos Luiz; SILVA, Lucas Gonçalves; SILVEIRA, Vladimir Oliveira da. Anais III Jornada Interamericana de Direitos Fundamentais e I Seminário Nacional da Rede Brasileira de Pesquisa em Direitos Fundamentais. Organização Rede Brasileira de Pesquisa em Direitos Fundamentais. São Paulo: RBPDF, 2017. p. 152-171. 